\title{
Aborto y discurso moral. Ideas clave de la Ética del discurso para el tratamiento de la interrupción voluntaria de la vida humana inicial
}

\author{
Abortion and Moral Discourse. Key Ideas of Discourse Ethics \\ for the Treatment of Voluntary Interruption of Inicial Human \\ Life
}

DORANDO MICHELINI*

\begin{abstract}
Resumen: El presente texto aborda la problemática del aborto como una cuestión moral, y deja de lado otros enfoques relevantes (por ejemplo, pragmáticos y éticos), dado que estos, en opinión del autor, no tienen como horizonte último el punto de vista moral. A partir de los presupuestos conceptuales y metodológicos de la Ética del discurso, en tanto que ética de la corresponsabilidad solidaria no rigorista, se presentan conceptos ético-discursivos que pueden fundamentar las dos tesis siguientes: a) La interrupción arbitraria de la vida humana en la etapa inicial de desarrollo es una práctica injusta; b) En determinados contextos de interacción y en situaciones específicas de decisión, el principio moral que exige no interrumpir voluntariamente la vida humana inicial puede ser no aplicable o su aplicación no exigible. Palabras clave: Aborto, Ética del discurso, fundamentación moral, aplicabilidad y exigibilidad del principio moral
\end{abstract}

\begin{abstract}
The present text addresses the problem of abortion as a moral issue, and leaves aside other relevant approaches (e.g. pragmatic and ethical), since these, in the author's opinion, do not have the moral point of view as their ultimate horizon. From the conceptual and methodological assumptions of Discourse Ethics, as ethics of non-rigorous solidary co-responsibility, discourse-ethical concepts are presented that can support the following two theses: a) The arbitrary interruption of human life in the initial stage of development is an unjust practice; b) In certain contexts of interaction and in specific situations of decision, the moral principle that demands not voluntarily interrupting the initial human life may not be applicable or its application may not be enforceable.
\end{abstract}

Keywords: Abortion, Discourse Ethics, moral foundation, applicability and enforceability of the moral principle.

Recibido: 05/06/2019. Aceptado: 01/08/2019.

* Profesor jubilado de la Universidad Nacional de Río Cuarto e investigador Principal del Consejo de Investigaciones científicas y tecnológicas de Argentina (CONICET). Últimas publicaciones: D. J. Michelini, "Zusammenleben in der Vielfalt. Ethik und Interkulturalität in einer globalen Welt“", en Margit Eckholt (Hg.), Religion als Ressource befreiender Entwicklung, Stuttgart: Matthias Grünewald Verlag, 2019, pp. 255-264. D. J. Michelini, Argumentos y creencias. ¿Es posible traducir los contenidos de fe al lenguaje secular?, en Domingo García Marzá y otros (coords.), Ética y filosofía política. Homenaje a Adela Cortina, 2018, pp. 165-176. Correo electrónico: michelini.rio@gmail.com 


\section{Introducción}

En los debates públicos sobre el aborto, la problemática del estatuto moral del feto ha sido abordada de modos muy diferentes. De hecho, hay distintos puntos de vista tanto sobre la determinación del inicio de la vida humana como desde qué momento o etapa de desarrollo debe protegerse moralmente la vida humana inicial. Además, puede pensarse que la problemática del estatuto moral del feto es un asunto tan complejo y controvertido, que antes que ocuparse de cuestiones éticas y filosóficas, lo mejor es ocuparse y preocuparse por cuestiones más concretas (medidas de salud pública relacionadas con el aborto y sus consecuencias, resolución de asuntos económicos, sociales, políticos y jurídicos vinculados con la interrupción legal del embarazo, etcétera). En mi opinión, el abordaje del estatuto moral del feto humano -más allá de las dificultades inherentes al tratamiento del problema del aborto en general- sigue siendo una cuestión ético-filosófica clave que no debe ser abandonada en favor del planteo de problemas instrumentales y pragmáticos, que obviamente es importante y que puede aparecer incluso como más realista.

La teoría clásica de la ética del discurso no tiene una posición única sobre el aborto y los pensadores ético-discursivos han llegado a resultados diversos al reflexionar sobre esta problemática. Jürgen Habermas sostiene, por ejemplo, que en la medida que la problemática del aborto se plantee como una cuestión moral -es decir, como un asunto de imparcialidad y de justicia-, con el tiempo podría llegarse a tener una respuesta definitiva que sea igualmente buena para todos; en cambio, si se trata de un problema ético -es decir, de un problema que debe resolverse en base a valores individuales o a criterios históricos y culturales de un grupo o una comunidad-, habría múltiples respuestas vinculadas con los distintos proyectos de vida, con las diversas formas culturales de comprender la problemática y con las distintas visiones éticas que remiten a las identidades de los individuos y las comunidades. De las diversas interpretaciones del mundo y de las divergentes formas de vida se seguirían distintas comprensiones éticas del aborto. (Habermas, 2000: 172s.) Por su parte, Karl-Otto Apel no ha presentado ningún escrito sobre la problemática del aborto. Sin embargo, en encuentros personales mantenidos en Alemania, entre los años 1987 y 1989, Apel me reiteró en varias ocasiones que, según su apreciación, la problemática del aborto pertenecía al ámbito de las decisiones personales de la mujer. Con ello parece claro que Apel no consideraba al aborto como un asunto moral, sino como una cuestión propia de la ética y del ámbito de la responsabilidad individual.

Dietrich Böhler -uno de los principales discípulos de Karl-Otto Apel- ha abordado el tema de forma explícita. En el texto titulado „Was heisst und wo beginnt Menschenwürde?“ (“¿Qué significa y dónde comienza la dignidad humana?”), Böhler sostiene que en el discurso práctico "no podemos poner en duda de manera creíble ni la irrebasabilidad de la pretensión de dignidad humana, ni el potencial de pérdida de razón que nos acompaña a lo largo de toda la vida" (Böhler, 2013: 532), y que los interlocutores discursivos poseen el mandato moral de proteger la dignidad humana incluso en aquellas fases de desarrollo en que los argumentantes no son capaces de racionalidad y discurso. Teniendo esto en claro, Böhler se pregunta cuál sería el estatuto moral de los embriones, y si ellos deben ser protegidos por el principio de la dignidad humana. 
Böhler considera que el fundamento normativo de la Ética del discurso reside en que quien ingresa en un discurso práctico se convierte en un interlocutor discursivo que pretende vincularidad para sus opiniones. La vincularidad que establece el discurso práctico representa una base común, más allá de los disensos fácticos que puedan darse entre proponentes y opositores, y entre quienes defienden o critican una determinada posición. Los interlocutores discursivos pueden coincidir así en la irrefutabilidad del procedimiento discursivo, a pesar de la falibilidad, la duda y el disenso que puedan ponerse de manifiesto en los planteos de cuestiones fácticas. Ahora bien, en los discursos prácticos es necesario tomar en serio tanto aquellas instancias racionales que resultan incuestionables como también todo aquello que remite a la falibilidad humana. En consecuencia, los interlocutores discursivos tienen que hacerse cargo no sólo de aquello que puede ser considerado irrefutable desde el punto de vista racional, sino también la duda, la incertidumbre y la ignorancia.

Dado que en los discursos prácticos deben hacerse valer tanto los presupuestos irrebasables de la argumentación -no exclusión de ningún afectado, igualdad discursiva, exclusión del engaño y exclusión de violencia (Habermas, 2006: 56s.)- como también la ponderación de las situaciones y los contextos de acción, al plantear la cuestión del estatuto moral del feto, los interlocutores discursivos deben responsabilizarse, desde el punto de vista moral, por asegurar las condiciones materiales de existencia y de desarrollo cada vez más autónomo de la personalidad moral humana.

Böhler, siguiendo a Jonas, remite a un principio de precaución y afirma: “Ante la duda, a favor de la vida y de la dignidad humana, lo que significa, a favor de la no-disponibilidad de embriones, es decir a favor de la protección de su dignidad humana" (Böhler, 2013: 537). Sin embargo, la ignorancia y la incertidumbre sólo puedan generarse en situaciones concretas de aplicación del principio moral, pero no en la cuestión relativa al inicio de la vida humana.

Más allá de estas reflexiones provenientes de los representantes clásicos de la Ética del discurso, la teoría ético-discursiva ofrece un conjunto de conceptos clave que permite abordar con coherencia teórica y práctica la problemática moral del aborto en tanto que interrupción voluntaria de la vida humana inicial. En mi opinión, y como mostraré a continuación, el aborto puede ser tratado como un asunto ético, pero también como un problema moral. Desde la perspectiva ética, entendida como la visión particular de un grupo o una comunidad, pueden darse múltiples respuestas a la problemática del aborto que remiten a las distintas formas de vida, a los valores vigentes en cada comunidad, a las distintas tradiciones y culturas, etcétera. Sin embargo, desde el punto de vista ético no es posible tratar el problema del aborto como un asunto de justicia, puesto que no están en juego intereses universalizables, sino solamente cuestiones que remiten a valoraciones personales y a visiones culturales diferentes, que pueden y deben ser resueltas como compromisos pragmáticos. En cambio, desde la perspectiva moral, la problemática del aborto puede y debe ser vista como un fenómeno que atañe a todos los interlocutores discursivos, porque afecta intereses de los miembros reales y virtuales de la comunidad ilimitada de comunicación. En este sentido, la interrupción voluntaria de la vida humana inicial es un problema que no debería ser abordado como un asunto que atañe exclusivamente a la racionalidad ética y pragmático-instrumental (y que, por ende, puede resolverse de forma estratégica o decisionista), sino también como una cuestión que presenta insoslayables interrogantes morales y requiere una solución justa. 
En lo que sigue, parto de la base de que, en relación con las discusiones en torno a la despenalización y legalización del aborto, la cuestión moral es un asunto clave. Hay distintos argumentos y exigencias que se esgrimen en orden a fundamentar la despenalización y la legalización del aborto, tanto de carácter positivo (se arguye a favor del derecho sexual y reproductivo de la mujer y del derecho a decidir; se exige que el aborto sea tratado como un asunto de salud pública; se afirma que la legalización del aborto ayuda a disminuir los abortos clandestinos y la mortalidad materna; se considera que la mujer es una persona, mientras que el embrión no lo es; se sostiene que la legalización del aborto ayuda a superar la desigualdad entre mujeres ricas y pobres, etcétera) como negativo (se afirma que la penalización es una medida ineficaz para evitar los abortos; que la prohibición del aborto lleva a la clandestinidad y a la realización de abortos no seguros, etcétera). Si bien es verdad que todas estas razones y exigencias tienen una importancia específica, no es menos cierto que cuando se trata de fundamentar la interrupción voluntaria del embarazo, la perspectiva moral desempeña, en mi opinión, un papel fundamental. En otros trabajos (Michelini, 2015; 2018) he sintetizado en dos tesis las formulaciones principales que, tomando como base los presupuestos conceptuales y metodológicos de la Ética del discurso, pueden hacerse sobre cuestiones de fundamentación y aplicación del principio moral en relación con la problemática del aborto, a saber:

a) La interrupción arbitraria de la vida humana inicial es, desde el punto de vista moral, una práctica injusta.

b) En determinados contextos de acción y en situaciones particulares de decisión, el principio moral que exige no interrumpir voluntariamente la vida humana inicial puede, con justas razones, no ser aplicable, o su aplicación puede no ser exigible.

En ambas tesis se trata exclusivamente de la interrupción voluntaria del embarazo. En la primera tesis, se entiende por interrupción arbitraria de la vida humana inicial aquella cesura voluntaria del embarazo que no puede justificarse con buenas razones ante la comunidad ilimitada de comunicación. La segunda tesis toma en consideración que, en determinadas circunstancias, pueden darse razones justas que limiten o impidan la aplicabilidad o la exigibilidad del principio moral de no interrupción voluntaria de la vida humana inicial.

Teniendo en cuenta que esta publicación forma parte del homenaje al maestro y amigo Karl-Otto Apel, quisiera explicitar algunos conceptos de la Ética del discurso, y especialmente de la obra de Apel, que me parecen sumamente útiles para abordar la problemática del aborto. Me referiré, en primer lugar, a la relevancia del punto de vista moral para la reflexión ético-filosófica en general y en relación con la problemática del aborto en particular. Luego explicitaré algunos de los conceptos clave de la Ética del discurso -comunidad ideal y comunidad real de comunicación, discurso práctico, libertad comunicativa, persona humana y a priori corporal- que ofrecen una base sólida para fundamentar la ilegitimidad de la interrupción arbitraria de la vida humana inicial. A continuación, y para finalizar, mostraré que la Ética del discurso en tanto que ética de la corresponsabilidad solidaria no rigorista ofrece también criterios de orientación para la fundamentación de la aplicabilidad y la exigibilidad del principio moral en determinados contextos históricos de interacción y en situaciones especiales de decisión. 


\section{El punto de vista moral}

La Ética del discurso afirma que el contenido de la moral anida en los presupuestos comunicativos universales de la argumentación y en el consenso que se obtiene por vía discursiva, apelando a buenas razones y con la participación de todos los afectados. La moral no remite a bienes y valores, sino a las relaciones entre sujetos capaces de acción, y a interacciones reguladas por normas que exigen vincularidad para todos. En todo proceso de socialización se incorporan conceptos tales como bueno y malo, correcto e incorrecto, justo e injusto, y se los relaciona con el comportamiento cotidiano propio y de los otros. Por razón práctica se entiende la capacidad de evaluar y justificar la corrección o incorrección de las acciones propias y de los demás en un determinado contexto de interacción. La razón práctica opera, según ha destacado Habermas, de forma distinta según se refiera a lo adecuado y útil, a lo bueno o a lo justo (Habermas, 2000: 109ss.). En consecuencia, las cuestiones pragmáticas, éticas y morales, en las que están en juego distintos puntos de vista (el técnico-práctico, el ético y el moral) deben ser tratadas de forma diferente (Habermas, 1998: 305).

El juicio técnico-práctico se orienta exclusivamente por el criterio pragmático de la adecuabilidad de los medios para alcanzar un fin propuesto o un propósito del agente moral. Los juicios éticos remiten al conjunto de valores, normas, deberes, tradiciones, etcétera que orientan la conducta y el juicio de los individuos en el marco de un grupo, una comunidad o una sociedad; son autorreferenciales, refieren a la propia identidad y a cómo deben entenderse los individuos dentro de una comunidad. El punto de vista moral representa aquella instancia desde la cual las cuestiones morales pueden decidirse con imparcialidad. (Habermas, 2000: 17) Este punto de vista, que se expresa en la universalizabilidad de las normas, no tiene un carácter sustantivo, sino formal-procedural. El punto de vista moral que se expresa en la universalizabilidad de las normas permite diferenciar entre lo que es bueno y lo que es justo o correcto: entre lo que es bueno para mí o para nosotros, y lo que es bueno para todos por igual. A diferencia de los compromisos pragmáticos y de las soluciones que pueden hallarse en el marco de las interrelaciones éticas de un grupo o una comunidad cultural determinada, el punto de vista moral representa la única alternativa seria para la resolución justa y no violenta de conflictos.

En mi opinión, a partir de la propuesta conceptual, criteriológica y metodológica de la Ética del discurso puede mostrarse, en primer lugar, que el aborto es una cuestión moral, y no un asunto que incumbe solo a la racionalidad ética o a la racionalidad pragmática. Para ello me valdré del análisis de los siguientes conceptos clave de la Ética del discurso: comunidad ideal y comunidad real de comunicación, discursos prácticos, libertad comunicativa, persona humana y a priori corporal, lo cual me permitirá explicitar y fundamentar la tesis de la exigencia moral de no interrupción arbitraria de la vida humana inicial. A continuación mostraré asimismo que la Ética del discurso, en tanto que ética de la corresponsabilidad solidaria no rigorista, permite sostener y fundamentar una segunda tesis, a saber: que el principio moral no debe ser aplicado siempre y en forma absoluta en todo contexto de interacción, abstrayendo de la realidad histórica y cultural. Dicho de otra forma: en determinados contextos de interacción y en situaciones especiales de decisión, el principio moral puede ser, con justa razón, no aplicable, o su aplicación puede ser no exigible. 


\section{Comunidad ideal y comunidad real de comunicación}

El concepto apeliano de comunidad ideal de comunicación, (Apel, 1975, II: 341ss.; 1988: 141), que Habermas denomina situación ideal de habla, reúne los criterios por los que deben orientarse en sus acciones y decisiones los interlocutores discursivos en tanto que miembros de la comunidad ideal de comunicación. Entre otros, cabe mencionar, en primer lugar, el concepto de inclusión radical, el cual expresa que en los discursos prácticos deben incluirse todos los intereses que puedan ser defendidos con buenos argumentos ante la comunidad ilimitada de comunicación y a todos los afectados, entre los que se cuentan no sólo los argumentantes actuales sino también los interlocutores virtuales. (Apel, 1975, II: 403) En segundo lugar, los intereses que pueden justificar los interlocutores discursivos con buenas razones y buenos argumentos desde el punto de vista moral son aquellos a los que pueden atribuírseles una "capacidad universal de validez" (Böhler, 2013: 512). En tercer lugar, los interlocutores discursivos, orientados por el principio de conservación, tienen la obligación moral de asegurar la supervivencia del género humano, y mediante una estrategia de emancipación deben intentar realizar la comunidad ideal de comunicación en la comunidad real de comunicación: "El primer objetivo constituye la condición necesaria del segundo, y el segundo confiere al primero su sentido; el sentido que ya está anticipado en cada argumento" (Apel, 1985, II: 409). Entre el principio de conservación y el principio de emancipación hay una tensión que debe ser resuelta a largo plazo. El principio de conservación requiere que se mantenga todo aquello que sea compatible con la comunidad ideal de comunicación, mientras que el principio de emancipación exige que se remuevan los obstáculos que dificultan o impiden la realización de discursos prácticos. Esta doble tarea implica crear condiciones para que las normas morales puedan ser aplicables y exigibles.

Los interlocutores discursivos deben asumir así corresponsable y solidariamente la responsabilidad moral por los miembros de la comunidad real de comunicación; más aún, quienes pertenecen "a una clase o raza oprimidas cuentan con un privilegio moral a priori frente a los privilegiados socialmente: tienen derecho a la realización de la igualdad, aún con anterioridad a las reglas de juego que sólo pueden aceptarse suponiendo la igualdad real" (Apel, 1985, II: 405). Y desde un punto de vista político, en sociedades democráticas, pluralistas y diversas, la legitimación de normas que pretendan vincularidad intersubjetiva debe apoyarse en razones que contemplen todos los intereses en juego y sean accesibles a todos los miembros de la comunidad de comunicación.

En relación con la problemática del aborto, la idea de inclusión radical implica que los fetos deben ser considerados, cuanto menos, como miembros virtuales de la comunidad ilimitada de comunicación. Si bien es verdad que los fetos no pueden intervenir como argumentantes en un discurso práctico para defender sus necesidades e intereses, no es menos cierto que los interlocutores discursivos pueden percatarse de que hay buenas razones para no excluir arbitrariamente a ningún miembro actual o virtual de la comunidad de comunicación, y que, por ende, la conservación y el cuidado del proceso unitario de devenir humano son susceptibles de validación universal. La no interrupción arbitraria de la vida humana inicial debe ser concebida así como un asunto de corresponsabilidad solidaria y como la exigencia moral de los interlocutores discursivos de no excluir a ningún miembro de la comunidad ilimitada de comunicación interrumpiendo el proceso unitario de devenir humano. 


\section{Discursos prácticos}

El discurso práctico es un procedimiento argumentativo que sirve para examinar críticamente las pretensiones de validez que se ponen de manifiesto cada vez que hacemos uso de expresiones prácticas: por ejemplo, cuando hacemos una propuesta o afirmamos o negamos algo. En un discurso práctico, los argumentantes pueden examinar y juzgar imparcialmente los intereses en juego apoyándose exclusivamente en buenas razones, así como resolver de forma racional y justa los conflictos, averiguando si una norma es capaz de hallar el asentimiento de todos los afectados y expresar aquello que todos podrían querer y de los que todos podrían hacerse cargo. En este sentido, desde el punto de vista moral puede considerarse justa una máxima de acción cuyo seguimiento general resulte bueno para todos por igual, e injusta, si ella no representa aquello que todos pueden querer y reconocer como universalmente justo.

Como complemento del principio de universalización habermasiano, Apel introduce un principio de fundamentación de aplicación referido a la historia, el cual expresa: "Obra sólo según una máxima de la que puedes suponer - sobre la base de un entendimiento real con los afectados o, respectivamente, de sus abogados o - en su lugar - a raíz de un experimento mental correspondiente - que las consecuencias y acciones colaterales que resultan previsiblemente de su realización general para la satisfacción de los intereses de cada uno de los afectados puedan ser aceptados sin coerción por todos los afectados en un discurso racional" (Apel, 1988: 123). Esta exigencia moral de los interlocutores discursivos es relevante para el abordaje de todos los problemas morales, como pueden ser las reflexiones en torno a la obligación moral de los miembros actuales de la comunidad real de comunicación respecto de las generaciones futuras y del cuidado de la vida humana inicial de todos los seres humanos. En el caso del aborto, la exigencia de ponderar imparcialmente los intereses relevantes y las necesidades de todos los afectados va unida a la obligación moral de los interlocutores discursivos de conservar y asegurar advocatoriamente, o mediante un experimento mental, las condiciones materiales de existencia de una personalidad moral.

De acuerdo con lo expuesto, los discursos prácticos permiten a los interlocutores discursivos no sólo precisar de forma justa los intereses de la mujer y de los demás afectados que participan efectivamente en el discurso, sino también delimitar de forma imparcial las obligaciones de los argumentantes respecto de la conservación y el cuidado de la vida humana inicial de los miembros virtuales de la comunidad ilimitada de comunicación.

Con ello queda claro que, a diferencia de lo que sostiene Frontalini Rekers (2018), en los discursos prácticos no están supra-valorados los virtuales derechos del feto, ni tampoco están infra-representados los intereses actuales de la mujer. Por el contrario, los problemas y dilemas que surgen en relación con la problemática del aborto provienen, en buena parte, del hecho de que en determinados contextos de acción se plantea el problema de que una vida puede ser salvada solo a costa de la otra, independientemente de que la vida del feto y la vida de la mujer posean la misma dignidad y merezcan el mismo respeto desde el punto de vista moral. Los dilemas morales y las situaciones límites de interacción tienen lugar justamente cuando hay que decidir, sin otra alternativa posible, entre salvar la vida de la mujer o la del feto, siendo que ambas vidas son igualmente valiosas y poseen la misma dignidad. Si la vida del feto y la vida de la mujer no fueran igualmente valiosas, no tendríamos un dilema moral. Visto desde cualquier otro punto de vista que no sea el moral podría pensarse que la vida de la 
mujer tendría que ser más y mejor valorada que la del feto. Podría aducirse, por ejemplo, que una de las razones por la que la vida de la mujer debería ser considerada más valiosa que la del feto fuera que ella detenta un desarrollo biológico, psicológico o intelectual superior. Sin embargo, el mayor o menor grado de desarrollo biológico o psicológico, el mayor o menor grado de inteligencia, la mayor o menor experiencia que tenga una persona o las diversas formas de entender la calidad de vida (Zavadivker, 2005) pueden ser relevantes en muchos sentidos (por ejemplo, para la ciencia, la sociedad, el desarrollo profesional, etcétera), pero no lo son para lo que denominamos dignidad de la vida humana desde el punto de vista moral.

\section{Libertad comunicativa}

La Ética del discurso rescata la idea kantiana de autonomía, vinculada con la libertad de la conciencia individual y la capacidad de ligar la propia voluntad al principio moral, pero busca superarla con un concepto de autonomía basado en la intersubjetividad, la cual remite a la libertad comunicativa. Desde el punto de vista ético-discursivo, la libertad comunicativa debe ser comprendida como un bien fundamental. En este sentido, Böhler (2013: 511) sostiene que la libertad comunicativa, en contraposición a la arbitrariedad, es "un bien discursivo y moral originario e irrebasable", por dos razones clave, a saber: por un lado, porque todo interlocutor discursivo la presupone inevitablemente al usar el lenguaje; por otro lado, "ningún interlocutor discursivo puede menoscabar este bien a otro interlocutor, sin poner en juego su propia credibilidad y socavar el discurso" (Böhler, 2013: 12).

Con este giro hacia la autonomía intersubjetiva, la voluntad autolegisladora ya no se concibe de modo presocial, sino que está ligada a la argumentación discursiva y se orienta a determinar lo que todos pueden querer en común. "La noción intersubjetiva de autonomía hace justicia al hecho de que el libre desarrollo de la personalidad de cada uno depende de la realización de la libertad de todas las personas". (Habermas, 2000: 28) La formación discursiva de la voluntad articula así intrínsecamente "la autonomía de individuos incanjeables" con "formas de vida intersubjetivamente compartidas" (Habermas, 2000: 76). En consonancia con ello, los mandatos morales, al pretender ser buenos para todos por igual, no plantean "pretensiones supererogatorias" o, dicho de otra forma, las acciones supererogatorias no pueden "justificarse moralmente" (Habermas, 2000: 79s., 144).

Cabe distinguir entonces entre autonomía discursiva y autarquía. (Michelini, 2007a; 2007b) A la idea de autarquía le es inherente un concepto monológico de decisión: no alude a aquello que, en base a razones convincentes, todos podrían querer como bueno para todos por igual, sino a la arbitrariedad. Quien decide al margen o en contra de los discursos prácticos, ignorando o desconociendo las exigencias morales de los interlocutores discursivos y su pertenencia a la comunidad de argumentantes, actúa de forma individualista y decisionista. Actuar de forma decisionista implica cortar la reflexión y la argumentación con el otro, y erigirse en autoridad única en lo que respecta a la toma de decisión. En este sentido, el decisionista confunde validez con decisión: Lo válido moralmente no remite a una fundamentación respaldada en las buenas razones, sino a una decisión individual y arbitraria.

La autonomía discursiva arraiga, por el contrario, en la intersubjetividad: La información, la consulta y la consideración de todos los intereses en juego son algunos elementos fundamentales que deben ser tenidos en cuenta por los agentes morales a la hora de tomar 
una decisión. Las decisiones de los interlocutores discursivos quiebran la arbitrariedad monológica, porque son tomadas en vista de la corresponsabilidad solidaria de todos los argumentantes: Se trata de decisiones que pueden estar fácticamente condicionadas por diversas instancias sociales, económicas, políticas, jurídicas y culturales, pero que tienen una raíz moral, puesto que se generan en vistas del criterio de reciprocidad generalizada y de aquello que es bueno para todos por igual.

El aborto es una práctica que tiene un amplio y complejo alcance en las relaciones humanas (afectivas, simbólicas, sociales, psicológicas, etcétera), por lo que la interrupción de la vida humana inicial no debe ser una cuestión de decisión monológica de la mujer. En este sentido, y tal como he expresado en otro lugar, "una ley del aborto que permita interrumpir libremente el embarazo en cualquier etapa de desarrollo del feto, sin apelar a razones convincentes, invocando exclusivamente el derecho o el deseo de la mujer, o la decisión monológica y decisionista de uno de los cónyuges, puede ser legítima desde la perspectiva jurídico-política, pero es injusta desde el punto de vista moral" (Michelini, 2018: 12). El no apelar a razones convincentes, que puedan ser validadas en un discurso práctico, significa decidir de forma monológica y arbitraria. Por el contrario, una decisión autónoma configurada en forma de libertad comunicativa sería aquella que se basa en el resultado de un discurso práctico en el que participan todos los afectados, se tienen en cuenta todos los intereses y se ha buscado articular la mejor información disponible con los mejores argumentos para asegurar la conservación y el cuidado de las condiciones materiales de existencia de una personalidad moral y del devenir de una personalidad moral.

\section{Persona humana y a priori corporal}

En un sentido típico-ideal, la Ética del discurso concibe a la persona humana como interlocutor discursivo, esto es, como un ser lingüística y comunicativamente competente, que actúa y decide en consonancia con los criterios de la comunidad ideal de comunicación. Los interlocutores discursivos son capaces de dar, recibir y exigir razones en vistas a cuestionar y solventar pretensiones de validez normativas. Ahora bien, en un discurso práctico, los interlocutores discursivos pueden percatarse de que no es pensable el desempeño argumentativo sin presuponer el cuerpo propio. Lo que inspirándome en una formulación de K.-O. Apel denomino a priori corporal (Apel, 1994: 155, 1987; Molina Molina, 2019a, 2019b) representa una condición sine qua non para el surgimiento de la moralidad: Sin vida humana y sin cuerpo propio, sin lenguaje, identidad genética, identidad social, cultura, etcétera no es pensable ningún desempeño discursivo de los argumentantes. Es por ello que los interlocutores discursivos son no sólo argumentantes potenciales y falibles, sino también personas potenciales. En este sentido es esclarecedora la siguiente afirmación de Böhler:

"Desde el punto de vista empírico somos incapaces de expresar pretensiones, incluso en la etapa de mayor madurez, por ejemplo durante el sueño, en una enfermedad grave o bajo los efectos de la anestesia. La incapacidad de discurso está latente durante toda nuestra vida. Ella es el otro lado de la potencial capacidad de razón o discurso de la vida humana: dado que los seres humanos existen única y exclusivamente como seres corpóreos, como un gran organismo finito y necesitado, pueden 
existir solo en una "necesitada libertad" (Jonas); por eso, en última instancia, no son 'seres racionales', como nos asegura la tradición, sino seres necesitados, que nunca poseen la capacidad racional de forma permanente, ni siquiera en el estadio más vigoroso de desarrollo. Los seres corpóreos son simultáneamente tan capaces como incapaces de racionalidad y discurso" (Böhler, 2013: 530).

Los argumentantes que ingresan a un discurso práctico han reconocido "que no somos sujetos autosuficientes y plenamente racionales, sino también interdependientes y emocionales" (Bonete Perales, 2018: 47; Cortina, 2007). Esto significa que los seres humanos somos seres que podemos alcanzar certezas y que no debemos renunciar al diálogo racional argumentativo al abordar los asuntos de interés común y al tratar de resolver problemas y conflictos morales, pero también, a la vez, somos seres falibles que debemos hacernos responsables por aquellas instancias que implican duda e incertidumbre, y que no pueden ser resueltas (al menos provisoriamente) mediante buenas razones y argumentos convincentes.

En relación con la problemática del aborto, y a partir de lo que puede constatarse en un discurso práctico -a saber: que la posibilidad de desempeño argumentativo de los interlocutores discursivos está indisolublemente articulada con la realidad del cuerpo propio- puede sostenerse que, para los seres humanos, la adquisición de personalidad moral está intrínsecamente relacionada con el resguardo de las condiciones materiales de vida que requiere el proceso unitario de devenir humano. Entre las condiciones materiales de existencia de una personalidad moral y del devenir una personalidad moral se cuentan, en el caso de los seres humanos, tanto la realidad del genoma humano como la inserción en un proceso de socialización que abarca fenómenos síquicos, afectivos, simbólicos y culturales. La existencia de la personalidad moral y el desempeño argumentativo están así indisolublemente ligados al devenir de cada vida humana, con su identidad genética y su identidad social.

La vida humana, al ser condición material del surgimiento de la moralidad, merece respeto. El aborto es una práctica que cercena - de una vez y de forma definitiva- el devenir de la vida humana y, con ello, toda posibilidad de existencia de una personalidad moral y de desempeño discursivo. En consecuencia, los interlocutores discursivos están obligados moralmente a no interrumpir de forma arbitraria el devenir de un ser humano en su etapa inicial de desarrollo, puesto que la cesura de dicho proceso cancela la existencia de una personalidad moral de forma absoluta y definitiva.

Es necesario destacar, sin embargo, que la comprensión de la vida humana como un proceso único e irrepetible del devenir humano, que no debe ser arbitrariamente interrumpido, no está exenta de incertidumbre, duda y falibilidad. Así, por ejemplo, en los discursos públicos parece no haber consenso sobre el inicio de la vida humana ni tampoco sobre el estatuto moral del feto. Sin embargo, desde la Ética del discurso puede sostenerse, con buenas razones, que no hay duda ni incertidumbre respecto de la obligación moral de los interlocutores discursivos respecto de actuar de forma responsable y solidaria en la conservación y el cuidado de la vida humana en todas las etapas del devenir humano. En el caso del aborto, el actuar con precaución (Böhler, 2013: 536) ante situaciones de duda y de incertidumbre sólo puede referirse a aspectos pragmáticos de aplicación del principio moral, no a la exigencia moral fundamental de la obligación de los argumentantes respecto del cuidado y de la protección de las condiciones materiales de desarrollo que requiere la 
estructura unitaria del proceso de devenir humano. Dicho de otra forma, la incertidumbre debe ser entendida como resultado de la no coincidencia total entre la comunidad real de comunicación y la comunidad ideal de comunicación. El plexo de irracionalidad inherente a la comunidad real de comunicación (violencia, estrategia, etc.) modaliza, complejiza y a menudo dificulta la aplicación de los criterios de validación de la acción práctica anticipados contrafácticamente en la comunidad ideal de comunicación.

Los argumentantes pueden constatar en un discurso práctico que los interlocutores discursivos, en tanto que seres corporales, son seres finitos, que se van desarrollando de forma imperfecta y limitada a través de un proceso biológico-social único e irrepetible; que están dotados de una capacidad de racionalidad y autonomía que se articula con otras capacidades e instancias no racionales; y que su desempeño discursivo sólo es posible en el marco de una comunidad real de comunicación. En definitiva, los interlocutores discursivos pueden cerciorarse de que son constitutivamente seres corpóreos -racionales y no racionales- durante toda su vida. En mi opinión, la eliminación arbitraria de la vida humana y del cuerpo propio -con su identidad genética (configurada fundamentalmente por la singularidad del genoma humano) y su identidad social (vinculada, por ejemplo, con relaciones -por cierto iniciales y rudimentarias- de afectividad) (Michelini, 2018)- debería ser concebida, en vista del principio de conservación, como una acción incompatible con las exigencias morales que provienen de la comunidad ideal de comunicación. Interrumpir arbitrariamente la vida humana inicial implica afectar intereses de la comunidad real de comunicación, por lo cual el aborto debe ser considerado una práctica incompatible con la reciprocidad generalizada de intereses. En consecuencia, los interlocutores discursivos están obligados moralmente a no interrumpir arbitrariamente la vida humana en ninguna etapa de desarrollo, puesto que ello representa una práctica injusta, dado que lesiona aspectos relacionados tanto con la preservación de la vida humana, en tanto que presupuesto de la comunidad real de comunicación, como con exigencias de no exclusión provenientes de la comunidad ideal de comunicación.

En síntesis: De lo expuesto hasta aquí sobre los conceptos básicos de la Ética del discurso (punto de vista moral, comunidad ideal y comunidad real de comunicación, discursos prácticos, libertad comunicativa, persona humana y a priori corporal) y su posible articulación con la fundamentación de la ilegitimidad moral de la interrupción arbitraria de la vida humana inicial puede retenerse lo siguiente: El lenguaje y la comunicación, posibilitadas por el cuerpo propio, constituyen características clave de aquellos seres que la Ética del discurso considera de forma típico-ideal como personas humanas. En el discurso práctico, los interlocutores discursivos pueden percatarse de que son seres corporales, y que sin cuerpo propio no es posible el desempeño discursivo de los argumentantes ni la existencia de una personalidad moral humana. La legitimidad de la prohibición del aborto radica en que la interrupción arbitraria de la vida humana en el estadio inicial de desarrollo es, desde el punto de vista moral, una práctica injusta. El aborto es -en principio, y desde un punto de vista moral formal- una práctica arbitraria e injusta, porque excluye no sólo intereses, sino también a miembros virtuales de la comunidad de comunicación. Ahora bien, la Ética del discurso -en tanto que ética de la corresponsabilidad solidaria no rigorista- se ocupa no sólo de la fundamentación abstracta y formal de la moral, sino también de la fundamentación de la aplicación referida a la historia del principio moral. Esta perspectiva de corresponsabilidad solidaria no rigorista pone bajo otra luz la aplicación concreta y realista del principio moral. 


\section{La Ética del discurso como ética de la corresponsabilidad solidaria no rigorista: aplicabilidad y exigibilidad del principio moral}

La Ética del discurso, en tanto que ética de la corresponsabilidad solidaria no rigorista, parte de la base de que toda buena fundamentación de las normas morales debe contemplar no sólo la fundamentación formal abstracta del principio moral, sino también la fundamentación de la aplicación del principio moral universal a situaciones históricas concretas y a contextos de acción condicionados por la cultura, la religión y los sistemas de autoafirmación, como la economía y la política.

\subsection{Fundamentación de la aplicación referida a la historia del principio moral}

La fundamentación ético-filosófica de las normas morales muestra las razones en que se apoya el juicio moral, el cual aspira a ser universal (es decir, válido y vinculante para todo ser racional). Desde este punto de vista, la idea de corresponsabilidad solidaria refiere a que los interlocutores discursivos están moralmente obligados a tomar en consideración los intereses de todos los afectados y a determinar, en base a buenas razones, aquello que todos podrían querer y que, en consecuencia, resulta ser bueno para todos por igual. La fundamentación referida a la historia de la aplicación del principio moral remite a las condiciones y los dilemas con los que se enfrentan las normas bien fundamentadas al pretender eficacia práctica.

La Ética del discurso expresa que los juicios morales, si bien están exentos de la dependencia contextual que caracteriza a los juicios éticos, deben tomar en consideración no sólo el principio de universalización, sino también las consecuencias colaterales de la acción. Tanto Habermas como sobre todo Apel han insistido en la relevancia que posee el contexto de acción para la fundamentación de la aplicación referida a la historia de las normas morales. Habermas afirma que el comportamiento moral implica actuar "siempre con arreglo a normas válidas correctamente aplicadas" (Habermas, 2000: 202), y que, por lo general, los problemas de aplicación de normas cuya validez podemos dar por supuesta, "revisten incluso mayor urgencia que los problemas de fundamentación". (Habermas, 2000: 91) Es por ello que la Ética del discurso no es insensible al contexto, y el punto de vista moral, plasmado en la universalizabilidad de normas, de ningún modo impide que se tomen en cuenta la situación individual y el contexto de acción de los interlocutores discursivos al momento de fundamentar o aplicar normas morales. Apel ha dedicado incluso una parte especial de su ética (la parte "B") al tratamiento de la fundamentación referida a la historia de las normas morales. (Apel, 1988: 134)

Ahora bien, la teoría ética no puede desconocer o ignorar que entre lo universal y lo particular, entre la exigencia del principio moral universal y las situaciones concretas de interacción hay tensiones y conflictos que deben ser resueltos de forma racional y responsable. Mientras que la parte "A" de la Ética del discurso remite a las condiciones ideales, contrafácticamente anticipadas, que necesariamente presuponen los argumentantes, la parte "B" da cuenta de las particularidades de la fundamentación de la aplicación en las situaciones históricas y fácticas en que deben llevarse adelante los discursos prácticos. Para superar la distancia entre las condiciones ideales y los condicionamientos fácticos, Apel introduce un "Principio de complementación" (Apel, 1988: 149), el cual contiene dos exi- 
gencias normativas, a saber: la primera obligación moral de los interlocutores discursivos es de tipo emancipador e implica colaborar en la búsqueda de consenso y en la superación de los obstáculos que impiden la realización de discursos prácticos; la segunda obligación moral es la de conservación de todos los logros e institucionalizaciones compatibles con los parámetros de la comunidad ideal de comunicación, lo cual implica que los agentes morales deben responsabilizarse también por las decisiones particulares que tomen -incluso haciendo uso de la racionalidad estratégica- en vista de los sistemas de autoafirmación. Dicho de otra forma, los interlocutores discursivos deben poner en juego en la vida real tanta racionalidad comunicativa como sea posible, y tanta racionalidad estratégica como sea necesaria.

La Ética del discurso, en tanto que ética de la corresponsabilidad solidaria no rigorista, sostiene que el principio de universalización no puede ni debe ser aplicado siempre de forma directa y absoluta, ignorando o desconociendo los efectos colaterales de las acciones. La fundamentación moral no debe ser ciega frente a las situaciones singulares y los contextos particulares de acción que, por ejemplo, ponen en riesgo la existencia de los agentes morales. El cumplimiento no rigorista del principio moral que exige no interrumpir arbitrariamente la vida humana en ninguna etapa de desarrollo vale también para la toma de decisión autónoma (no autárquica) de los interlocutores discursivos en el caso del aborto. Es importante destacar que para el cumplimiento no rigorista del principio moral, los interlocutores discursivos deben guiarse por el criterio de la comunidad ideal de comunicación: éste constituye la guía no sólo para aquellas acciones que se desarrollan en el marco de la racionalidad comunicativa, sino también para la toma de decisión en aquellos contextos de interacción en que los interlocutores discursivos deben hacer uso de la racionalidad estratégica, limitando o suspendiendo la aplicación del principio moral. (Romero, 2016) Al mismo tiempo obliga a cambiar aquellas situaciones que imposibilitan la aplicación responsable del principio moral. En este sentido, la idea de corresponsabilidad solidaria toma en cuenta siempre también las condiciones de interacción social como condicionamientos para la realización plena del principio moral. Es por ello que los interlocutores discursivos pueden comprobar en el discurso práctico no sólo la ilegitimidad moral de la interrupción arbitraria de la vida humana en la etapa inicial de desarrollo, sino también ponderar las condiciones de aplicabilidad y exigibilidad del principio moral en determinados contextos de interacción y en situaciones especiales de decisión.

\subsection{Aplicabilidad y exigibilidad del principio moral}

En vista de la fundamentación de las normas morales, la Ética del discurso exige que se tomen en cuenta las consecuencias directas e indirectas que previsiblemente se deriven del seguimiento general de las normas consensuadas. El principio de universalización no exime a los interlocutores discursivos de considerar las exigencias que provienen de las coerciones fácticas y de los sistemas de autoafirmación (Apel, 2000). Esto significa que el principio moral, si bien nunca pierde su validez de principio, no debe ser aplicado rigurosamente siempre y en toda situación; más aún, en determinados contextos históricos de interacción y situaciones especiales de decisión, el principio moral puede ser no aplicable o su aplicación puede ser no exigible. 
Una norma moral bien fundamentada debe tomar en consideración no sólo la exigencia abstracta universal del principio moral, sino también los condicionamientos de interacción y las situaciones individuales de decisión. La validez formal de los principios morales debe ser articulada tanto con las condiciones históricas de aplicabilidad, como con las situaciones individuales de exigibilidad del principio moral. Con el concepto de condiciones históricas de aplicabilidad se hace referencia, por ejemplo, a que las situaciones contextuales e institucionales de interacción deben ofrecer alternativas razonables de decisión; a su vez, la no aplicabilidad del principio moral puede darse en aquellas circunstancias en las que los agentes morales ven restringida al máximo su capacidad de decisión por coerciones sistémicas y estructurales. A diferencia de ello, el concepto de exigibilidad alude a las cargas que surgen de las decisiones que tome el agente moral y que él debe asumir responsablemente. Ante situaciones dramáticas y dilemáticas, los agentes morales pueden -e incluso deben- actuar de forma estratégico-contraestratégica, y limitar o incluso suspender la aplicación del principio moral.

En relación con la problemática del aborto, esta interpretación ético-discursiva no rigorista de la corresponsabilidad solidaria implica que el principio moral de no interrumpir arbitrariamente la vida humana en la etapa inicial de desarrollo puede ser no aplicable en determinados contextos de interacción, o no exigible en situaciones especiales de decisión. Por un lado, la problemática de la aplicabilidad del principio moral de no interrupción arbitraria de la vida humana inicial tiene que ver con el ordenamiento general de la sociedad (con las estructuras jurídicas, políticas e institucionales) y con los condicionamientos económicos, sociales, educativos y culturales que restringen a tal punto el contexto de interacción, que los agentes morales se ven privados de una alternativa razonable para la aplicación del principio moral. Este sería el caso, por ejemplo, cuando un régimen político prohíbe tener hijos, y exige que, por razones de Estado, las mujeres embarazadas aborten, puesto que de lo contrario les esperan sanciones gravísimas. La mujer embarazada que se ve enfrentada a semejante amenaza no tiene una real libertad para tomar una decisión moral, y, por ende, para aplicar de forma no rigorista el principio de no interrupción voluntaria de la vida humana inicial, puesto que ello podría implicar que su familia tenga que afrontar consecuencias gravísimas, o que ella incluso pueda perder la vida.

Por otro lado, la no exigibilidad de la aplicación del principio moral remite no a condiciones del ordenamiento general de una sociedad, sino a circunstancias personales dramáticas (como la violación) o a situaciones particulares de falta de información, falta de formación o de claridad ante dudas e incertidumbres a la hora de tener que tomar la decisión de aplicar el principio moral. Hay circunstancias y situaciones personales dramáticas en las que los interlocutores discursivos se ven enfrentados a dilemas morales, ante los cuales deben tomar una decisión en conciencia y con el mejor conocimiento posible. Una situación dilemática se plantea cuando alguien tiene que decidir entre dos obligaciones morales igualmente exigibles, pero que no pueden cumplimentarse ambas a la vez; más aún, el cumplimiento de una implicaría necesariamente el incumplimiento de la otra. Esta falta de alternativa moralmente razonable se da, por ejemplo, cuando una mujer se enfrenta a una situación en la que tiene que optar entre salvar su vida a costa de la vida del feto, o salvar la vida del feto a costa de su propia vida. Para estos casos en que se evidencian tanto las limitaciones de los interlocutores discursivos, como así también la finitud humana y la imposibilidad de hallar 
una respuesta razonable de aplicación del principio moral, la Ética del discurso no exige acciones supererogatorias y delega la decisión última a la conciencia de los agentes morales.

La Ética del discurso no puede obviamente determinar de antemano qué ha de ser considerado en cada caso como una situación grave para la salud e integridad física y psicológica de la mujer: ello debería ser abordable y explicitable en un discurso práctico. Lo que sí puede afirmarse desde la perspectiva de la Ética del discurso, en tanto que ética de la corresponsabilidad solidaria no rigorista, es que la mujer no puede ser obligada moralmente en circunstancias de no aplicabilidad y no exigibilidad del principio moral a realizar el acto supererogatorio de dar su vida para salvar la del hijo, aunque obviamente puede hacerlo por otras razones y desde cualquier otro punto de vista, por ejemplo, desde el punto de vista de una creencia religiosa.

En el marco de la Ética del discurso, la aplicabilidad y exigibilidad del principio moral están relacionadas no sólo con la articulación responsable entre racionalidad estratégica y racionalidad comunicativa, sino también con la calidad de los ordenamientos legales, el nivel de realización social de las normas jurídicas, el abordaje responsable de los problemas y los dilemas que surgen en el mundo real al momento de aplicar el principio moral y, no en última instancia, con la posibilidad de realización e institucionalización de los discursos prácticos. Es por ello que la Ética del discurso, en tanto que ética de la corresponsabilidad solidaria no rigorista, sostiene que la aplicabilidad y la exigibilidad del principio moral son elementos constitutivos de una buena fundamentación moral. En este sentido, la aplicación del punto de vista moral (un punto de vista que, en sí mismo, no pierde nunca su validez) puede ser limitada en determinados contextos de interacción y suspendida en situaciones singulares de decisión.

En síntesis: En determinados contextos de interacción y en situaciones dilemáticas de acción y decisión, el principio moral que exige no interrumpir arbitrariamente la vida humana inicial puede no ser aplicable, o su aplicación puede no ser exigible.

\section{Reflexión final}

En los discursos prácticos, los interlocutores discursivos saben, en tanto que miembros de la comunidad ideal de comunicación, que la validez de sus afirmaciones depende del cumplimiento de instancias lingüísticas y comunicativas irrebasables, anticipadas contrafácticamente, y que, en tanto que miembros de la comunidad real de comunicación, pueden descubrir la inevitabilidad del cuerpo propio y reconocer que sin identidad genética y sin identidad social no es posible para los seres humanos ingresar en un discurso práctico y autocomprenderse como personas morales. En tanto que miembros de la comunidad ideal de comunicación, los argumentantes no sólo son responsables de ponderar las necesidades, los intereses y los derechos de quienes efectivamente pueden participar en un discurso práctico, sino que también están obligados a tomar en consideración -de modo advocatorio, o en forma de un experimento mental- la conservación y el cuidado de las condiciones materiales de vida de los miembros virtuales de la comunidad ilimitada de comunicación. A la vez, desde el punto de vista de la Ética del discurso en tanto que ética de la corresponsabilidad solidaria no rigorista puede sostenerse que la exigencia moral de no interrupción voluntaria de la vida humana inicial puede ser, con buenas razones, no aplicable en determinados contextos históricos de interacción, o su aplicación puede no ser exigible en situaciones peculiares de decisión. Aún ante casos límites y ante situaciones dilemáticas, los interlocutores discursivos 
deben reflexionar y decidir en conciencia, en vista de los mejores conocimientos disponibles y tomando en consideración las instancias últimas de validez que aporta el criterio de la comunidad ideal de comunicación.

Podría pensarse que el aborto, dado el escaso consenso que resulta de las discusiones ético-filosóficas sobre su legalidad o ilegalidad, debe ser tratado pragmáticamente, como un asunto que atañe fundamentalmente a la salud pública, al derecho y a la política. A diferencia de la abstracción y las interminables e intrincadas discusiones filosóficas, que no suelen llevar a una toma de decisión concreta, el tratamiento pragmático de la problemática del aborto permitiría avanzar en soluciones más realistas, sobre la base de compromisos entre las partes, que, por cierto, tienen -y muy probablemente seguirán teniendo- opiniones diversas. En mi opinión, no caben dudas de que hay innumerables problemas prácticos, políticos y jurídicos que deben ser adecuadamente tratados y resueltos. Sin embargo, ignorar o desconocer la relevancia filosófica del punto de vista moral cuando se trata de abordar la problemática de la interrupción voluntaria de la vida humana en el estado inicial de desarrollo implica abandonar el único punto de vista desde el cual esta problemática puede ser regulada no sólo en forma de compromisos pragmáticos y éticos, sino también de forma justa, de modo que resulte buena para todos por igual, sin excepciones ni acepciones de personas.

La Ética del discurso de Karl-Otto Apel, que fue elaborada en tensión crítica con el pensamiento de Jürgen Habermas, es no solamente sólida y esclarecedora desde el punto de vista teórico, sino que se muestra también como sumamente eficaz y productiva para dilucidar problemáticas concretas que surgen en el mundo histórico. En este sentido, desde el punto de vista de la Ética del discurso pudo mostrarse que el aborto es, en principio, una práctica injusta y, a la vez, que la fundamentación de la aplicación histórica del principio moral ofrece un instrumentario conceptual y metodológico que va más allá de las distintas formas de rigorismo ético tradicional, lo cual permite precisar y ponderar críticamente el alcance de la responsabilidad moral en distintos ámbitos de interacción.

\section{Referencias}

APEL, K.-O., (1963), “Das Leibapriori der Erkenntnis. Eine Erkenntnisanthropologische Betrachtung im Anschluss an Leibnizens Monadenlehre“, en: Archiv für Philosophie 12, 1: pp. 152-172

APEL, K.-O., (1985), La transformación de la filosofía, 2 Tomos, Madrid: Taurus.

APEL, K.-O. (1987), „Fallibilismus, Konsenstheorie der Wahrheit und Letztbegründung“, en: Forum für Philosophie Bad Homburg (ed.), Philosophie und Begründung, Frankfurt am Main: Suhrkamp, pp. 116-211.

APEL, K.-O. (1988), Diskurs Verantwortung, Suhrkamp: Frankfurt am Main.

APEL, K.-O. (1994), "Fundamentación semiótico-trascendental de la filosofía pragmática del lenguaje”, en: K.-O. Apel, Semiótica filosófica, Buenos Aires: Almagesto. Trad. de Ricardo Maliandi.

APEL, K.-O. (2000), "Ética del discurso y globalización. La ética ante las coerciones fácticas e institucionales de la político, el derecho y la economía”, Diálogo con Dorando J. Michelini (Niedernhausen/Ts., 27 de abril de 1999), en: Erasmus II, 2, pp. 99-119. 
APEL, K.-O., D. Böhler, G. Kadelbach (eds.) (1984), Praktische Philosophie/Ethik: Dialoge 2, Frankfurt am Main: Fischer Verlag.

BÖHLER, D. (2013), „Was heisst und wo beginnt Menschenwürde“, en: D. Böhler, Verbindlichkeit aus dem Diskurs. Denken und Handeln nach der Wende zur kommunikativen Ethik. Orientierung in der ökologischen Dauerkrise, Freiburg-München, Verlag KarlAlber, pp. 529-538.

BONETE PERALES, E. (2018), “Adela Cortina: en torno a la dignidad de las personas”, en: Domingo García Marzá et al. (coords.), Ética y filosofía política. Homenaje a Adela Cortina, Madrid: Tecnos, pp. 37-51.

CORTINA, A. (2007), Ética de la razón cordial: Educar en la ciudadanía en el siglo XXI, Oviedo: Nobel

FRONTALINI REKERS, R. (2018), "Comentario crítico al libro de Dorando J. Michelini, El desafío de dar razones: la problemática del aborto desde la perspectiva de una ética de la corresponsabilidad solidaria no rigorista", Río Cuarto: Ediciones del ICALA, en: Revista Ética y Discurso, 3, 1, 169-180, disp. en https://www.icala.org.ar/RED/E+D/ E+D-3-1-2018/07-E+D-1-2018-Frontalini.pdf

HABERMAS, J. (1998), Facticidad y validez. Sobre el derecho y el Estado democrático de derecho en términos de teoría del discurso, Madrid: Trotta.

HABERMAS, J. (2000), Aclaraciones a la Ética del discurso, Trotta: Madrid.

HABERMAS, J. (2006), Entre naturalismo y religión, Barcelona: Paidós.

MICHELINI, D. J. (2007a), „Die primordiale kommunikativ-diskursive Autonomie. Zu Ehren von Karl-Otto Apel anlässlich seines 85. Geburstags“, en M. Borrelli / M. Kettner (eds.), Laudatio in honorem Karl-Otto Apel, Cosenza: Luigi Pellegrini Editore, pp. 77-83.

MICHELINI, D. J. (2007b), „Diskurs und Autonomie“, en: M. Borrelli / M. Kettner (eds.), Filosofia trascendentalpragmatica, Cosenza: Luigi Pellegrini Editore, pp. 355-375.

MICHELINI, D. J. (2015), "El aborto como cuestión moral. Una perspectiva ético-discursiva”, en: Revista Redbioética/UNESCO, 6, 2 (12), pp. 101-114, disp. en: https://redbioetica.com.ar/wp-content/uploads/2018/11/Art7-Michelini-Revista12.pdf.

MICHELINI, D. J. (2018), El desafío de dar razones. La problemática del aborto desde la corresponsabilidad solidaria no rigorista, Río Cuarto, Ediciones del ICALA, disp. en https://www.icala.org.ar/publicaciones/Libros-EdICALA/DJMichelini-El\%20 desaf\%C3\%ADo\%20de\%20dar\%20razones-2018.pdf.

MOLINA MOLINA, L. (2019a), Cuerpo y lenguaje en la filosofía de K.-O. Apel. Hacia una integración de la antropología del conocimiento y la pragmática trascendental del lenguaje. Tesis doctoral. Granada: Universidad de Granada, 2019.

MOLINA MOLINA, L. (2019b), "Los a priori del conocimiento en la filosofía de Karl-Otto Apel. De la gnoseo-antropología a la pragmática trascendental del lenguaje", en: Revista Ética y Discurso 4,1 (en prensa)

ROMERO, E. O. (2016), “¿Qué hace un filósofo cuando dice que fundamenta? Relaciones programática en torno a Kant, la Ética del discurso y un diálogo posible sobre la problemática del aborto", en: Revista ERASMUS, XVIII, 1, pp. 49-59

ZAVADIVKER, M. N. (2005), "Reflexiones sobre el aborto desde una ética de la calidad de la vida", en: Revista Persona, 44, disp. en www.revistapersona.com.ar/Persona44/ 44Zavadivker.htm. 
